\title{
Chemical composition of lipophilic extractives from sisal (Agave sisalana) fibers
}

\author{
Ana Gutiérrez*, Isabel M. Rodríguez, José C. del Río \\ Instituto de Recursos Naturales y Agrobiología de Sevilla, CSIC, PO Box 1052, E-41080 Seville, Spain
}

\section{A R T I C L E I N F O}

\section{Article history:}

Received 15 May 2007

Received in revised form

22 January 2008

Accepted 24 January 2008

\section{Keywords:}

Agave sisalana

Ferulic acid esters

Lipids

Nonwood fibers

Pitch

Sisal

\begin{abstract}
A B S T R A C T
The chemical composition of lipophilic extractives from sisal (Agave sisalana) fibers, which are used for high-quality paper pulp production, was studied. The lipophilic extract, which accounted for $0.5 \%$ of total sisal fiber weight, was analyzed by gas chromatography (GC) and gas chromatography/mass spectrometry (GC/MS) using short- and medium-length high temperature capillary columns, respectively. For a more detailed characterization, the extract was fractionated by solid-phase extraction and the fractions obtained were analyzed by GC and GC/MS. The most predominant compounds identified were fatty acids $(30 \%$ of total lipids) including $\alpha$ - and $\omega$-hydroxyfatty acids, fatty alcohols $(20 \%)$, free sterols $(11 \%)$, alkanes $(11 \%)$ and a series of ferulic acid esters of long chain alcohols and $\omega$-hydroxyfatty acids $(10 \%)$. Additionally, steroid hydrocarbons and ketones, monoglycerides, aldehydes, waxes, and sterol glycosides were also found together with minor amounts of diglycerides, and sterol esters.
\end{abstract}

(c) 2008 Elsevier B.V. All rights reserved.

\section{Introduction}

Although wood is still by far the main raw material for paper pulp manufacturing in developed countries, a market exists for high-value added papers from nonwood fibers. Indeed, their prices are higher as compared to wood kraft pulp. Moreover, where wood-based fibers are not available, as in the developing world, nonwood plants are the dominant fiber source for papermaking (van Dam et al., 1994; Moore, 1996).

Sisal (Agave sisalana) is an herbaceous monocotyledonous plant from the Agavaceae family. Originally from Central America and Mexico, sisal grows in many tropical countries, with Tanzania and Brazil being currently the two main producers (Chand et al., 1998). Sisal fibers, which are obtained from the leaves of the plant, are widely used for many applications including ropes for the marine and agriculture industry, as well as composites (Li et al., 2000; Agopyan et al., 2005).
Likewise, sisal fiber has received increasing interest as raw material for the pulp and paper industry. The main characteristic of paper pulp obtained from sisal is its high porosity, making it an excellent raw material for papers such as dielectric, plug wrap, laminating substrate, vacuum bag, tea bag and filtration papers.

Studies on the chemical composition of sisal fibers are important for improving the pulping and bleaching processes of this raw material. Existing knowledge mainly includes general features of macromolecular components and the mechanical and physical properties of sisal fiber for composites application (Li et al., 2000) as well as few studies on the chemical composition of lignin (del Río et al., 2004a,b, 2007). To our knowledge, no studies about the chemical composition of sisal lipophilic extractives have been performed until now. In the present study, we report the detailed chemical composition of lipophilic compounds from sisal fibers with the aim

\footnotetext{
* Corresponding author. Tel.: +34 95 4624711; fax: +34 954624002.

E-mail address: anagu@irnase.csic.es (A. Gutiérrez).
} 
of providing knowledge of interest for pulp and paper manufacture using this fiber as raw material. As it is well known, lipophilic compounds present in raw materials cause the socalled pitch problems in the manufacturing of pulp and paper (Hillis and Sumimoto, 1989; Back and Allen, 2000). The knowledge of the composition of the lipophilic extractives present in this fiber may help to predict and control pitch problems in the manufacturing of sisal pulp.

\section{Materials and methods}

\subsection{Sample}

Sisal (A. sisalana) leaf fibers (from Africa) were supplied by CELESA pulp mill (Tortosa, Spain) that produces high-quality soda/antraquinone paper pulps from nonwoody plants. The plant fibers were air-dried, milled using a knife mill (Janke and Kunkel, Analysenmühle), and extracted with acetone in a Soxhlet apparatus for $8 \mathrm{~h}$. The acetone extracts were evaporated to dryness, and subsequently dissolved in chloroform for chromatographic analysis of the lipophilic fraction. Two replicates were used for each sample.

\subsection{Fractionation by solid-phase extraction (SPE)}

The SPE fractionation was used for a more detailed characterization of some compounds that eluted close together or were present in very minor amounts. The lipid extracts were fractionated by a SPE procedure previously developed by Gutiérrez et al. (1998, 2004a) using aminopropyl-phase cartridges $(500 \mathrm{mg}$ ) from Waters (Division of Millipore). In the SPE method described here, the lipophilic compounds are retained in the column and elute from the column in order of increasing polarity. The cartridge was loaded and eluted by gravity. The procedure for the fractionation of sisal lipophilic extractives was as follows. First, the aminopropyl column was conditioned with hexane $(4 \mathrm{ml})$. Next, the dried cloroform extract containing sisal lipophilic extractives was taken up in a minimal volume $(<0.5 \mathrm{ml})$ of hexane:chloroform (4:1) and loaded into the cartridge column, leaving the entire lipid mixture in the column. Next, the column was first eluted with $8 \mathrm{ml}$ of hexane (fraction A) and subsequently with $6 \mathrm{ml}$ of hexane:chloroform $(5: 1)$ (fraction $B$ ), then with $10 \mathrm{ml}$ of chloroform (fraction $\mathrm{C}$ ) and finally with $10 \mathrm{ml}$ of diethyl ether:acetic acid (98:2) (fraction D). Each isolated fraction was dried under nitrogen and subsequently dissolved in chloroform and analyzed by gas chromatography (GC) and gas chromatography/mass spectrometry (GC/MS).

\subsection{GC and GC/MS analyses}

The lipophilic extractives from sisal fibers were analyzed by GC and GC/MS using short- and medium-length high temperature capillary columns with thin films, respectively, as described below. This method enables the elution and analysis of intact high molecular mass lipids.

An HP 5890 gas chromatograph (Hewlett Packard, Hoofddorp, Netherlands) equipped with a split-splitless injector and a flame ionization detector (FID) was used for GC analyses.
The injector and the detector temperatures were set at $300^{\circ} \mathrm{C}$ and $350^{\circ} \mathrm{C}$, respectively. Samples were injected in the splitless mode. Helium was used as the carrier gas. The capillary column used was a high temperature, polyimide coated fused silica tubing DB5-HT ( $5 \mathrm{~m} \times 0.25 \mathrm{~mm}$ i.d., $0.1 \mu \mathrm{m}$ film thickness) from J\&W Scientific (Folsom, CA, USA), especially processed for use at $400^{\circ} \mathrm{C}$. The oven was temperature-programmed from $100^{\circ} \mathrm{C}(1 \mathrm{~min})$ to $350^{\circ} \mathrm{C}(3 \mathrm{~min})$ at $15^{\circ} \mathrm{C} \mathrm{min}{ }^{-1}$. Peaks were quantified by area, and a mixture of standards (octadecane, palmitic acid, sitosterol, cholesteryl oleate, and campesteryl, stigmasteryl and sitosteryl $3 \beta$-D-glucopyranosides) was used to elaborate calibration curves. The data from the two replicates were averaged. In all cases the standard deviations from replicates were below $10 \%$ of the mean values.

The GC/MS analyses were performed on a Varian Saturn 2000 (Varian, Walnut Creek, CA, USA) with an ion trap detector, equipped with a fused silica capillary column (DB5HT, J\&W; $15 \mathrm{~m} \times 0.25 \mathrm{~mm}$ i.d., $0.1 \mu \mathrm{m}$ film thickness). The oven was heated from $120^{\circ} \mathrm{C}(1 \mathrm{~min})$ to $380^{\circ} \mathrm{C}(5 \mathrm{~min})$ at $10^{\circ} \mathrm{C} \mathrm{min}^{-1}$. The injector and transfer line temperatures were set at $300^{\circ} \mathrm{C}$ and $350^{\circ} \mathrm{C}$, respectively. Helium was used as the carrier gas and the injection was performed in splitless mode. Trimethylsilyl-diazomethane methylation and bis(trimethylsilyl)trifluoroacetamide (BSTFA) silylation, in the presence of pyridine, were used when required. Compounds were identified by comparing their mass spectra with mass spectra in the Wiley and NIST libraries and with those reported in the literature, by mass fragmentography and, when possible, by comparison with authentic standards.

\section{Results and discussion}

The lipid content of sisal fibers accounted to $0.5 \%$ of total fiber weight. This value is similar to other nonwood fibers used for papermaking such as kenaf, hemp and abaca, and lower than flax (Gutiérrez and del Río, 2003a,b; Gutiérrez et al., 2004b, 2006; del Río and Gutiérrez, 2006). The underivatized, methylated and/or silylated extracts were analyzed by GC and GC/MS using short- and medium-length high temperature capillary columns, respectively, with thin films, according to the method previously described (Gutiérrez et al., 1998, 2004a). This method enables the elution and analysis of intact high molecular weight lipids such as waxes, sterol esters and triglycerides.

The GC/MS chromatogram of the underivatized lipid extract from sisal fibers is shown in Fig. 1 and the identities and abundances of the main lipophilic compounds are detailed in Table 1. For a better characterization of the compounds present, the total extract of the sisal fibers was subjected to SPE fractionation, according to the method previously developed (Gutiérrez et al., 1998, 2004a). In this SPE method, the lipophilic compounds are retained in the column and elute in order of increasing polarity. The chromatograms of the different SPE fractions obtained (A-D) are shown in Fig. 2. The first fraction (A), eluted with hexane, was enriched in alkanes, waxes and sterol esters. The second fraction (B), eluted with hexane:chloroform (5:1), contained alkyldioxolane series arising from the side-reaction of monoglycerides and acetone. The third fraction (C), eluted with chloroform, con- 
Table 1 - Composition of lipids ( $\mathrm{mg} / \mathbf{1 0 0} \mathrm{g}$ ) in sisal fibers

\begin{tabular}{|c|c|c|c|}
\hline Compounds & Mass fragments & MW & Abundance \\
\hline n-Alkanes & & & 10.07 \\
\hline n-Heneicosane & $\underline{57 / 71 / 85 / 296}$ & 296 & 0.14 \\
\hline$n$-Docosane & $57 / 71 / 85 / 310$ & 310 & 0.06 \\
\hline$n$-Tricosane & $\underline{57 / 71 / 85 / 324}$ & 324 & 1.50 \\
\hline n-Tetracosane & $\underline{57 / 71 / 85 / 338}$ & 338 & 0.18 \\
\hline n-Pentacosane & $\underline{57 / 71 / 85 / 352}$ & 352 & 4.58 \\
\hline n-Hexacosane & $\underline{57 / 71 / 85 / 366}$ & 366 & 0.39 \\
\hline n-Heptacosane & $\underline{57 / 71 / 85 / 380}$ & 380 & 2.54 \\
\hline n-Octacosane & $\underline{57 / 71 / 85 / 394}$ & 394 & 0.10 \\
\hline n-Nonacosane & $\overline{57 / 71 / 85 / 408}$ & 408 & 0.40 \\
\hline$n$-Triacontane & $\underline{57 / 71 / 85 / 422}$ & 422 & 0.04 \\
\hline n-Hentriacontane & $\underline{57 / 71 / 85 / 436}$ & 436 & 0.15 \\
\hline Fatty acids & & & 30.35 \\
\hline n-Tetradecanoic acid & $60 / \underline{73 / 129 / 228}$ & 228 & 0.27 \\
\hline n-Pentadecanoic acid & $60 / \underline{73 / 129 / 242}$ & 242 & 0.10 \\
\hline 9-Hexadecenoic acid & $\underline{55 / 69 / 236 / 254}$ & 254 & 0.08 \\
\hline n-Hexadecanoic acid & $60 / \underline{73 / 129 / 256}$ & 256 & 2.25 \\
\hline n-Heptadecanoic acid & $60 / 73 / 129 / 270$ & 270 & 0.12 \\
\hline 9,12-Octadecadienoic acid & $\underline{67 / 81 / 280}$ & 280 & 0.48 \\
\hline 9-Octadecenoic acid & $\underline{55} / 69 / 264$ & 282 & 1.68 \\
\hline n-Octadecanoic acid & $60 / 73 / 129 / 284$ & 284 & 0.71 \\
\hline$n$-Nonadecanoic acid & $60 / \underline{73} / 129 / 298$ & 298 & 0.02 \\
\hline n-Eicosanoic acid & $60 / 73 / 129 / 312$ & 312 & 0.18 \\
\hline n-Heneicosanoic acid & $60 / \underline{73 / 129 / 326}$ & 326 & 0.11 \\
\hline n-Docosanoic acid & $60 / \underline{73 / 129 / 340}$ & 340 & 1.22 \\
\hline n-Tricosanoic acid & $60 / \underline{73 / 129 / 354}$ & 354 & 0.55 \\
\hline n-Tetracosanoic acid & $60 / \underline{73} / 129 / 368$ & 368 & 2.22 \\
\hline n-Pentacosanoic acid & $60 / 73 / 129 / 382$ & 382 & 1.34 \\
\hline n-Hexacosanoic acid & $60 / \underline{73} / 129 / 396$ & 396 & 2.47 \\
\hline n-Heptacosanoic acid & $60 / \underline{73 / 129 / 410}$ & 410 & 0.61 \\
\hline n-Octacosanoic acid & $60 / 73 / 129 / 424$ & 424 & 2.93 \\
\hline n-Nonacosanoic acid & $60 / 73 / 129 / 438$ & 438 & 0.44 \\
\hline n-Triacontanoic acid & $60 / \underline{73 / 129 / 452}$ & 452 & 1.03 \\
\hline n-Dotriacontanoic acid & $60 / \underline{73} / 129 / 480$ & 480 & 0.09 \\
\hline n-Tetratriacontanoic acid & $60 / 73 / 129 / 508$ & 508 & 0.07 \\
\hline 2-Hydroxytetracosanoic acid & $73 / \underline{411} / 455^{a}$ & $470^{\mathrm{a}}$ & 2.16 \\
\hline 2-Hydroxypentacosanoic acid & $73 / 425 / 469^{a}$ & $484^{a}$ & 0.12 \\
\hline 22-Hydroxydocosanoic acid & $73 / 395 / 411 / \underline{427}^{\mathrm{a}}$ & $442^{\mathrm{a}}$ & 0.68 \\
\hline 24-Hydroxytetracosanoic acid & $73 / 423 / 439 / \underline{45}^{a}$ & $470^{\mathrm{a}}$ & 0.35 \\
\hline 26-Hydroxyhexacosanoic acid & $73 / 451 / 467 / \underline{483}^{a}$ & $498^{\mathrm{a}}$ & 4.04 \\
\hline 28-Hydroxyoctacosanoic acid & $73 / 479 / 485 / \underline{11}^{\mathrm{a}}$ & $526^{\mathrm{a}}$ & 4.05 \\
\hline Fatty alcohols & & & 18.37 \\
\hline n-Docosanol & $75 / 103 / \underline{38}^{a}$ & $398^{\mathrm{a}}$ & 0.49 \\
\hline n-Tetracosanol & $75 / 103 / 411^{a}$ & $426^{a}$ & 0.31 \\
\hline n-Hexacosanol & $75 / 103 / \underline{439}^{a}$ & $454^{\mathrm{a}}$ & 4.76 \\
\hline n-Octacosanol & $75 / 103 / \underline{467}^{\mathrm{a}}$ & $482^{\mathrm{a}}$ & 11.99 \\
\hline n-Triacontanol & $75 / 103 / \underline{495}^{a}$ & $510^{a}$ & 0.74 \\
\hline n-Dotriacontanol & $75 / 103 / \underline{523}^{a}$ & $538^{a}$ & 0.08 \\
\hline Aldehydes & & & 1.97 \\
\hline n-Heneicosanal & $\underline{82 / 96 / 292}$ & 310 & 0.07 \\
\hline n-Docosanal & $\underline{82 / 96 / 306}$ & 324 & 0.24 \\
\hline$n$-Tricosanal & $82 / 96 / 320$ & 338 & 0.20 \\
\hline n-Tetracosanal & $\underline{82 / 96 / 334}$ & 352 & 0.11 \\
\hline n-Pentacosanal & $\underline{82 / 96 / 348}$ & 366 & 0.20 \\
\hline n-Hexacosanal & $\underline{82 / 96 / 362}$ & 380 & 0.36 \\
\hline n-Octacosanal & $\underline{82 / 96 / 390}$ & 408 & 0.79 \\
\hline Steroid hydrocarbons & & & 3.90 \\
\hline Ergosta-3,5,7-triene & $\underline{135 / 143 / 380}$ & 380 & 0.04 \\
\hline Stigmasta-3,5,7-triene & $\underline{135 / 143 / 394}$ & 394 & 3.26 \\
\hline Stigmasta-3,5-diene & 81/147/381/396 & 396 & 0.64 \\
\hline
\end{tabular}


Table 1 (Continued)

\begin{tabular}{|c|c|c|c|}
\hline Compounds & Mass fragments & MW & Abundance \\
\hline Free sterols & & & 10.21 \\
\hline Campesterol & $\underline{55 / 145 / 213 / 382 / 400}$ & 400 & 0.38 \\
\hline Stigmasterol & $\overline{55} / 83 / 255 / 394 / 412$ & 412 & 1.73 \\
\hline Sitosterol & $\overline{145} / \underline{213 / 396 / 414}$ & 414 & 7.43 \\
\hline Stigmastanol & $215 / \overline{416}$ & 416 & 0.22 \\
\hline 7-Ketositosterol & $135 / 161 / 395 / 428$ & 428 & 0.45 \\
\hline Steroid ketones & & & 1.17 \\
\hline Stigmasta-3,5-dien-7-one & $\underline{174 / 269 / 410}$ & 410 & 0.51 \\
\hline Stigmast-4-en-3-one & $\overline{124} / 229 / 412$ & 412 & 0.34 \\
\hline Stigmast-4-en-3,6-dione & $137 / 398 / 408 / 411 / 426$ & 426 & 0.03 \\
\hline Stigmastane-3,6-dione & $245 / 287 / \underline{428}$ & 428 & 0.28 \\
\hline Waxes & & & 1.81 \\
\hline $\mathrm{C}_{40}$ & 57/71/257/592 & 592 & 0.03 \\
\hline $\mathrm{C}_{42}$ & $57 / 71 / 257 / 620$ & 620 & 0.15 \\
\hline $\mathrm{C}_{44}$ & $57 / 71 / 257 / 285 / 648$ & 648 & 0.57 \\
\hline $\mathrm{C}_{46}$ & $57 / 71 / 285 / 313 / 676$ & 676 & 0.72 \\
\hline $\mathrm{C}_{48}$ & $\underline{57 / 71 / 313 / 704}$ & 704 & 0.19 \\
\hline $\mathrm{C}_{50}$ & $57 / 71 / 313 / 341 / 752$ & 732 & 0.16 \\
\hline Sterol esters & & & 0.21 \\
\hline Sitosterol esters & $\underline{147 / 255 / 381 / 396}$ & & 0.21 \\
\hline Steryl glycosides & & & 0.97 \\
\hline Campesteryl 3ß-D-glucopyranoside & $204 / 217 / 361 / 383^{a}$ & $850^{\mathrm{a}}$ & 0.07 \\
\hline Stigmasteryl 3ß-D-glucopyranoside & $204 / 217 / 361 / 395^{a}$ & $862^{\mathrm{a}}$ & 0.20 \\
\hline Sitosteryl 3ß-D-glucopyranoside & $\underline{\underline{204}} / 217 / 361 / 397^{a}$ & $864^{\mathrm{a}}$ & 0.70 \\
\hline Monoglycerides & & & 2.99 \\
\hline 2,3-Dihydroxypropylhexadecanoate & 73/147/203/371/459a & $474^{\mathrm{a}}$ & 0.08 \\
\hline 2,3-Dihydroxypropyloctadec-9-enoate & $73 / 129 / 147 / 397 / 485^{a}$ & $500^{\mathrm{a}}$ & 0.05 \\
\hline 2,3-Dihydroxypropyloctadecanoate & $73 / 147 / 203 / 399 / 487^{a}$ & $502^{\mathrm{a}}$ & 0.04 \\
\hline 2,3-Dihydroxypropylhexacosanoate & $73 / 147 / 203 / 511 / 599^{a}$ & $614^{\mathrm{a}}$ & 0.65 \\
\hline 2,3-Dihydroxypropyloctacosanoate & $73 / 147 / 203 / 539 / 627^{a}$ & $642^{\mathrm{a}}$ & 1.59 \\
\hline 2,3-Dihydroxypropylnonacosanoate & $73 / 147 / 203 / 553 / 641^{\text {a }}$ & $656^{\mathrm{a}}$ & 0.11 \\
\hline 2,3-Dihydroxypropyltriacontanoate & $73 / 147 / 203 / 567 / 655^{a}$ & $670^{\mathrm{a}}$ & 0.46 \\
\hline Diglycerides & & & 0.28 \\
\hline 1,3-Dipalmitoylglycerol & $73 / 129 / 313 / 371 / 625^{a}$ & $640^{\mathrm{a}}$ & 0.12 \\
\hline 1,3-Palmitoylstearoylglycerol & $73 / 313 / 341 / 371 / 399^{a}$ & $668^{\mathrm{a}}$ & 0.09 \\
\hline 1,3-Distearoylglycerol & $73 / 129 / 341 / 399 / 653^{a}$ & $696^{\mathrm{a}}$ & 0.08 \\
\hline$n$-Alkyl ferulates & & & 9.15 \\
\hline trans-Eicosanyl ferulate & $137 / 177 / 194 / \underline{474}$ & 474 & $<0.01$ \\
\hline trans-Heneicosanyl ferulate & $137 / 177 / 194 / 488$ & 488 & 0.07 \\
\hline trans-Docosanyl ferulate & $137 / 177 / 194 / 502$ & 502 & 0.39 \\
\hline trans-Tricosanyl ferulate & $137 / 177 / 194 / 516$ & 516 & 0.15 \\
\hline trans-Tetracosanyl ferulate & $137 / 177 / 194 / \overline{530}$ & 530 & 0.91 \\
\hline trans-Pentacosanyl ferulate & $137 / 177 / 194 / 544$ & 544 & 0.20 \\
\hline trans-Hexacosanyl ferulate & $137 / 177 / 194 / 558$ & 558 & 3.11 \\
\hline trans-Heptacosanyl ferulate & $137 / 177 / 194 / 572$ & 572 & 0.11 \\
\hline trans-Octacosanyl ferulate & $137 / 177 / 194 / 586$ & 586 & 4.17 \\
\hline trans-Nonacosanyl ferulate & $137 / 177 / 194 / 600$ & 600 & $<0.01$ \\
\hline trans-Triacontanyl ferulate & $137 / 177 / 194 / 614$ & 614 & 0.05 \\
\hline$\omega$-Carboxyalkylferulates & & & 0.25 \\
\hline trans-Feruloyloxydocosanoic acid & $177 / 470 / 486 / 514$ & 532 & $<0.01$ \\
\hline trans-Feruloyloxytetracosanoic acid & $\overline{177} / 498 / 514 / 542$ & 560 & 0.04 \\
\hline trans-Feruloyloxyhexacosanoic acid & $177 / 526 / 542 / 570$ & 588 & 0.10 \\
\hline trans-Feruloyloxyoctacosanoic acid & $\underline{177} / 554 / 570 / 598$ & 616 & 0.11 \\
\hline trans-Feruloyloxytriacontanoic acid & $177 / 554 / 570 / 598$ & 616 & $<0.01$ \\
\hline
\end{tabular}

Main mass fragments and molecular weight (MW) are included.

a as TMS ether derivatives. Underlined mass fragments indicate base peaks. 


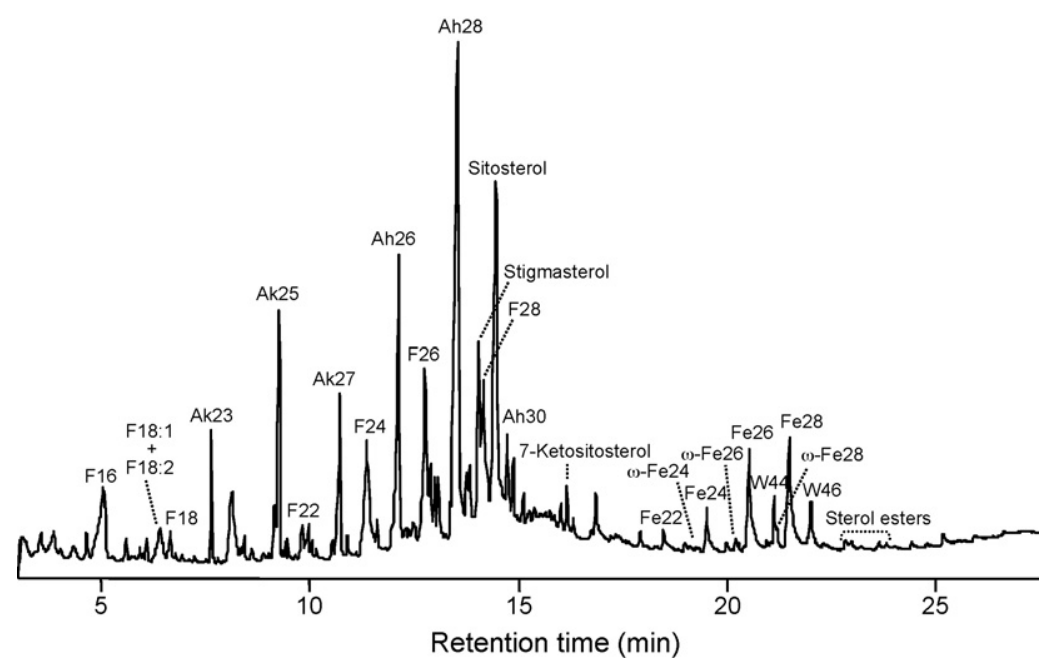

Fig. 1 - GC/MS chromatogram of the underivatized lipid extract of sisal fibers. Labeling for the different peaks are: $F(n)$ : $n$-fatty acids series; $\mathrm{Ak}(n)$ : $n$-alkanes series; $\mathrm{Ah}(n)$ : $n$-alcohols series; $\mathrm{Fe}(n): n$-alkylferulates series; $\omega$-Fe(n): $\omega$-carboxyalkylferulates series; $\mathrm{W}(n)$ : waxes series; $n$ denotes the total carbon atom number.

tained fatty alcohols, sterols and $n$-alkyl ferulates. A final fraction (D) enriched in free fatty acids and esters of ferulic acid with $\omega$-hydroxyfatty acids was eluted with diethyl ether-acetic acid (98:2).

The most predominant lipid classes present in sisal fibers were series of fatty acids ( $30 \%$ of total lipids) including $\alpha$ - and $\omega$-hydroxyfatty acids, fatty alcohols (20\%), alkanes (11\%), free sterols (11\%) and a series of ferulic acid esterified with long chain alcohols or with $\omega$-hydroxyfatty acids (10\%). Additionally, steroid hydrocarbons, monoglycerides, aldehydes, waxes, ketones and sterol glycosides were also found together with minor amounts of diglycerides, ferulic acids esterified and sterol esters.

Free fatty acids were identified ranging from tetradecanoic $\left(C_{14}\right)$ to tetratriacontanoic $\left(C_{34}\right)$ acids, with strong evenover-odd carbon atom predominance. Octacosanoic $\left(C_{28}\right)$, hexacosanoic $\left(C_{26}\right)$, palmitic $\left(C_{16: 0}\right)$ and tetracosanoic $\left(C_{24}\right)$ acids were the most abundant. Relatively high amounts of $\omega$-hydroxyfatty acids (ranging from $\mathrm{C}_{22}$ to $\mathrm{C}_{28}$ ) and $\alpha$ hydroxyfatty acids (ranging from $\mathrm{C}_{24}$ to $\mathrm{C}_{25}$ ) were also identified. $n$-Fatty alcohols were present in the sisal extracts ranging from $\mathrm{C}_{22}$ to $\mathrm{C}_{32}$ with a strong even-over-odd carbon atom predominance, octacosanol $\left(\mathrm{C}_{28}\right)$ being the most abundant. Interestingly, the series of free fatty alcohols parallels the distribution of the esterified fatty alcohols in waxes and in $n$-alkyl ferulates as described below. A series of $n$-alkanes ranging from $C_{21}$ to $C_{31}$ was also identified in the sisal fibers with a strong odd-over-even carbon atom number predominance, pentacosane $\left(\mathrm{C}_{25}\right)$ being the most predominant.

Sterols were also found in significant amounts among the lipids of sisal fibers. Sitosterol was the most abundant among the free sterols with the presence of minor amounts of campesterol, stigmasterol, stigmastanol and 7ketositosterol. Low amounts of sitosterol could also be found in ester form. Steryl glycosides, such as campesteryl, stigmasteryl and sitosteryl $3 \beta$-D-glucopyranosides were identified in minor amounts, the latter being the most predominant.
The identification of steryl glycosides was accomplished (after BSTFA derivatization of the lipid extract) by comparison with the mass spectra and relative retention times of authentic standards (Gutiérrez and del Río, 2001). Minor amounts of steroid hydrocarbons (stigmasta-3,5,7-triene and stigmasta-3,5-diene) and steroid ketones (stigmasta3,5-dien-7-one, stigmast-4-en-3-one, stigmast-4-en-3,6-dione and stigmastane-3,6-dione) were also identified.

Series of $p$-hydroxycinnamate esters consisting of ferulic acid esterified to long chain fatty alcohols $\left(\mathrm{C}_{20}-\mathrm{C}_{30}\right)$ and $\omega$ hydroxyfatty acids $\left(\mathrm{C}_{22}-\mathrm{C}_{30}\right)$ were also identified among the lipids of sisal fiber. The characterization of the individual compounds was achieved based on the mass spectra obtained by GC/MS of the underivatized and their methyl and/or TMS ether derivatives (del Río et al., 2004a,b). The series of $n$-alkyl transferulates, concentrated in alcoholic fraction of SPE (Fig. 2C), occurred in the range from $\mathrm{C}_{20}$ to $\mathrm{C}_{30}$, with the presence of both the even and odd carbon atom number homologues, $\mathrm{C}_{26}$ and $\mathrm{C}_{28}$ being the most prominent. The $\mathrm{C}_{26}$ and $\mathrm{C}_{28}$ also were the most abundant free fatty alcohols in sisal fiber, as described above. In contrast, in most wood and nonwoody plant species in which ferulic acid esters have been reported, $C_{22}$ and $C_{24}$ fatty alcohols were the dominant components esterifed to ferulic acid (Kolattukudy and Espelié, 1989; del Río et al., 2004a,b; del Río and Gutiérrez, 2006). n-Alkylferulates with odd-carbon number atoms have rarely been reported (Baldé et al., 1991). The series of $n$-alkyl ferulates identified occurred mostly in the trans-form, although some minor amounts of the cis-isomer were also observed at lower retention times.

On the other hand, ferulic acid was also found esterified with the hydroxyl group of $\omega$-hydroxyfatty acids. This series of compounds was concentrated in the acidic SPE fraction (Fig. 2D). The feruloyl ester-linked $\omega$-hydroxyfatty acids identified ranged from $C_{22}$ to $C_{30}$, the $C_{26}$ and $C_{28}$ homologues being the most abundant. The $\mathrm{C}_{26}$ and $\mathrm{C}_{28}$ homologues also were the most abundant $\omega$-hydroxyfatty acids present in free form. The odd members of the series were 

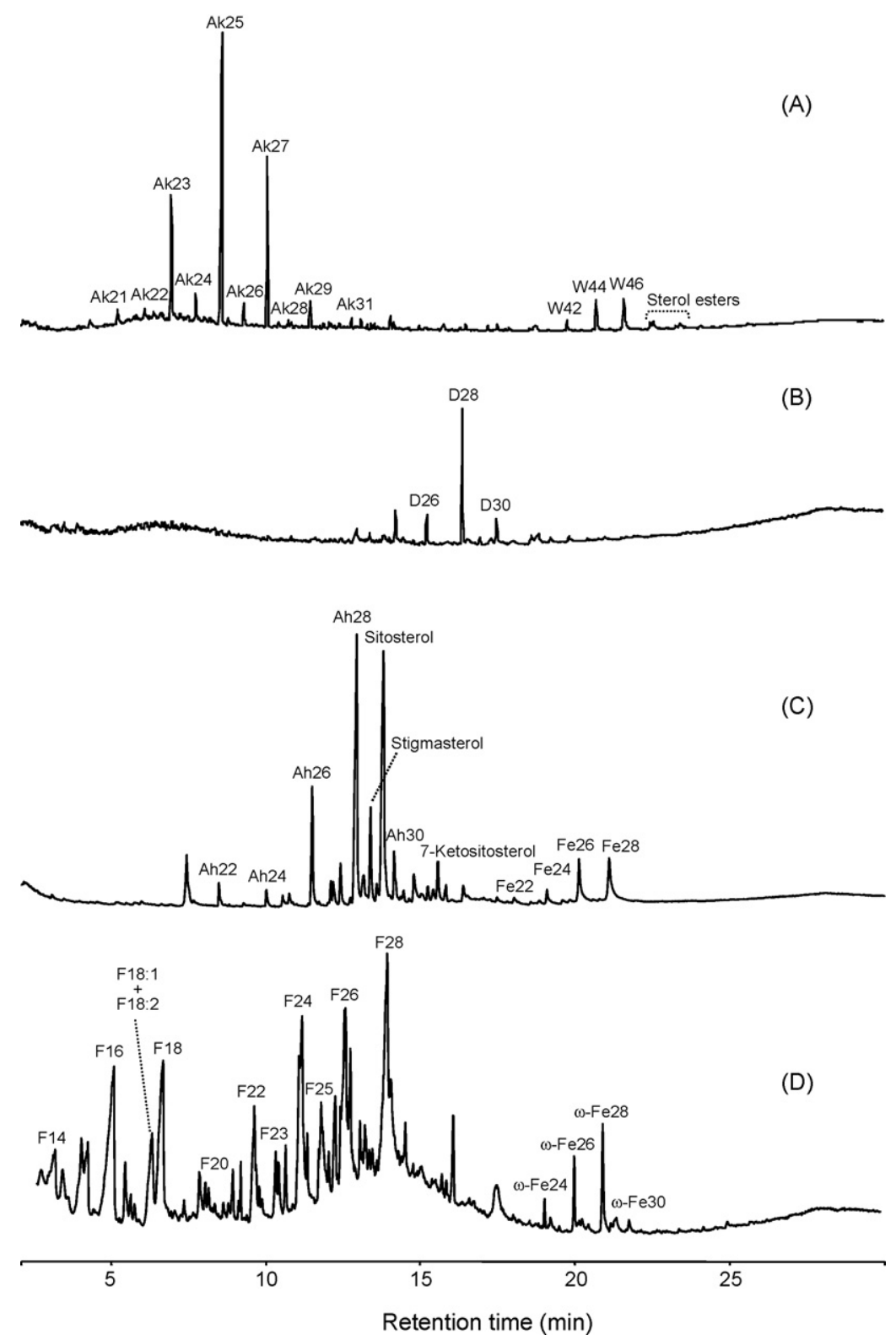

Fig. 2 - GC/MS chromatograms of the different SPE fractions isolated from sisal fibers extracts. (A) Fraction A, eluted with $8 \mathrm{ml}$ of hexane; (B) fraction B, eluted with $6 \mathrm{ml}$ of hexane:chloroform (5:1); (C) fraction C: eluted with $10 \mathrm{ml}$ of chloroform; (D) fraction D: eluted with $10 \mathrm{ml}$ of diethyl ether:acetic acid (98:2). Labeling for the different peaks are the same reflected in Fig. 1. $D(n)$ denotes the alkyldioxolane series arising from the side-reaction of monoglycerides and acetone.

not present in sisal fibers. Feruloyl esters of $\omega$-hydroxyfatty acids have been rarely reported in plants. A series of acidic esters derived from $C_{22}$ to $C_{29}$-hydroxyfatty acids and trans- and cis-ferulic acids was reported for the first time in Virola species (Kawanishi and Hashimoto, 1987) and has also recently been found in other plant species, including abaca (Musa textilis) (del Río et al., 2004a,b; del Río and Gutiérrez, 2006) and Eucalyptus globulus wood (Freire et al., 2002).

Finally, minor amounts of other compounds such as series of $n$-aldehydes (ranging from $\mathrm{C}_{21}$ to $\mathrm{C}_{28}$ ), mono- and diglycerides and waxes (from $\mathrm{C}_{40}$ to $\mathrm{C}_{50}$ ), were also identified among the sisal fiber extracts.
The pitch problems that the lipophilic extractives present in sisal fibers could originate will depend on the pulping (i.e. mechanical and chemical) process used. Some of the main lipophilic compounds of sisal fibers, such as alkanes, fatty alcohols, some fatty acids, and steroids have been reported to be stable under alkaline (soda/antraquinone) pulping of other nonwood fibers (Gutiérrez and del Río, 2003a,b; Gutiérrez et al., 2004b). The lipophilic extractives that survive pulping will present a different behavior during bleaching depending on their chemical structure and on the bleaching agent used (Jansson et al., 1995; Gutiérrez et al., 2001; Freire et al., 2006). Finally, the compounds that survive the bleaching process can be found as pulp extractives, and become a source of prob- 
lems in the paper machine. Some of the lipophilic compounds present in sisal fibers have been found in pitch deposits produced during the manufacturing of both totally chlorine free and elementary chlorine free pulps from different raw materials (del Río et al., 1998, 2000; Gutiérrez and del Río, 2005).

In conclusion, the present work reports the content and chemical composition of lipids of sisal fibers. The knowledge of the chemical composition of lipophilic extractives from these fibers will be useful for a better utilization of this interesting plant material.

\section{Acknowledgements}

This study has been supported by the Spanish Ministerio de Ciencia y Tecnología (MCYT) (projects AGL2002-00393 and AGL2005-01748) and EU project (BIORENEW, NMP2-CT-2006026456). We thank CELESA pulp mill (Tortosa, Spain) for providing the sisal fibers.

\section{REFERENCES}

Agopyan, V., Savastano Jr., H., John, V.M., Cincotto, M.A., 2005. Developments on vegetable fibre-cement based materials in Sao Paulo, Brazil: an overview. Cement Concrete Comp. 27, 527-536.

Back, E.L., Allen, L.H., 2000. Pitch Control, Wood Resin and Deresination. Tappi Press, Atlanta.

Baldé, A.M., Claeys, M., Pieters, L.A., Wray, V., Vlietinck, A.J., 1991. Ferulic acid esters from stem-bark of Pavetta owariensis. Phytochemistry 30, 1024-1026.

Chand, N., Tiwary, R.K., Rohatgi, P.K., 1998. Bibliography resource structure properties of natural cellulosic fibres-an annotated bibliography. J. Mater. Sci. 23, 381-387.

del Río, J.C., Gutiérrez, A., González-Vila, F.J., Martín, F., 1998. Characterization of organic deposits produced in the kraft pulping of Eucalyptus globulus wood. J. Chromatogr. A 823, 457-465.

del Río, J.C., Romero, J., Gutiérrez, A., 2000. Analysis of pitch deposits produced in kraft pulp mils using a totally chlorine free bleaching sequence. J. Chromatogr. A 874, 235-245.

del Río, J.C., Gutiérrez, A., Martínez, A.T., 2004a. Identifying acetlylated lignin units in non-wood fibers using pyrolysis-gas chromatography/mass spectrometry. Rapid Commun. Mass Spectrom. 18, 1181-1185.

del Río, J.C., Rodríguez, M.J., Gutiérrez, A., 2004b. Identification of intact long-chain $p$-hydroxycinnamate esters in leaf fibers of abaca (Musa textilis) using gas chromatography/mass spectrometry. Rapid Commun. Mass Spectrom. 18, 2691-2696.

del Río, J.C., Gutiérrez, A., 2006. Chemical composition of abaca (Musa textilis) leaf fibers used for manufacturing of high-quality paper pulps. J. Agric. Food Chem. 54, 4600-4610.

del Río, J.C., Martínez, A.T., Gutiérrez, A., 2007. Presence of 5-hydroxyguaiacyl units as native lignin constituents in plants as seen by Py-GC/MS. J. Anal. Appl. Pyrol. 79, 33-38.

Freire, C.S.R., Silvestre, A.J.D., Neto, C.P., 2002. Identification of new hydroxy fatty acids and ferulic acid esters in the wood of Eucalyptus globulus. Holzforschung 56, 143-149.
Freire, C.S.R., Silvestre, A.J.D., Neto, C.P., Evtuguin, D.V., 2006. Effect of oxygen, ozone and hydrogen peroxide bleaching stages on the contents and composition of extractives of Eucalyptus globulus kraft pulps. Biores. Technol. 97, 420-428.

Gutiérrez, A., del Río, J.C., González-Vila, F.J., Martín, F., 1998. Analysis of lipophilic extractives from wood and pitch deposits by solid-phase extraction and gas chromatography. J. Chromatogr. A 823, 449-455.

Gutiérrez, A., del Río, J.C., 2001. Gas chromatography/mass spectrometry demonstration of steryl glycosides in eucalypt wood, Kraft pulp and process liquids. Rapid Commun. Mass Spectrom. 15, 2515-2520.

Gutiérrez, A., Romero, J., del Río, J.C., 2001. Lipophilic extractives from Eucalyptus globulus pulp during kraft cooking followed by TCF and ECF bleaching. Holzforschung 55, 260-264.

Gutiérrez, A., del Río, J.C., 2003a. Lipids from flax fibers and their fate in alkaline pulping. J. Agric. Food Chem. 51 (17), $4965-4971$.

Gutiérrez, A., del Río, J.C., 2003b. Lipids from flax fibers and their fate in alkaline pulping. J. Agric. Food Chem. 51 (23), 6911-6914.

Gutiérrez, A., del Río, J.C., Martínez, A.T., 2004a. Chemical analysis and biological removal of wood lipids forming pitch deposits in paper pulp manufacturing. In: Spencer, J.F.T., Ragout de Spencer, A.L. (Eds.), Methods in Molecular Biology/Biotechnology. Environmental Microbiology: Methods and Protocols. Humana Press, Totowa, NJ, USA, pp. 191-204.

Gutiérrez, A., Rodríguez, I.M., del Río, J.C., 2004b. Chemical characterization of lignin and lipid fractions in kenaf bast fibers used for manufacturing high-quality papers. J. Agric. Food Chem. 52, 4764-4773.

Gutiérrez, A., del Río, J.C., 2005. Chemical characterization of pitch deposits produced in the manufacturing of high-quality paper pulps from hemp fibers. Biores. Technol. 96, 1445-1450.

Gutiérrez, A., Rodríguez, I.M., del Río, J.C., 2006. Chemical characterization of lignin and lipid fractions in industrial hemp bast fibers used for manufacturing high-quality paper pulps. J. Agric. Food Chem. 54, 2138-2144.

Hillis, W.E., Sumimoto, M., 1989. Effect of extractives on pulping. In: Rowe, J.W. (Ed.), Natural Products of Woody Plants II Springer-Verlag, Berlin, pp. 880-920.

Jansson, M.B., Wormald, P., Dahlman, P.O., 1995. Reactions of wood extractives during ECF and TCF bleaching of kraft pulp. Pulp Paper Can. 96, 42-45.

Kawanishi, K., Hashimoto, Y., 1987. Long chain esters of Virola species. Phytochemistry 26, 749-752.

Kolattukudy, P.E., Espelié, K.E., 1989. Chemistry, biochemistry, and function of suberin and associated waxes. In: Rowe, J.W. (Ed.), Natural Products of Woody Plants, vol. 1. Springer-Verlag, Berlin, pp. 304-367.

Li, Y., Mai, Y.-W., Ye, L., 2000. Sisal fibre and its composites: a review of recent developments. Comp. Sci. Technol. 60, 2037-2055.

Moore, G., 1996. Nonwood Fibre Applications in Papermaking. Pira International, Leatherhead, Surrey, UK.

van Dam, J.E.G., van Vilsteren, G.E.T., Zomers, F.H.A., Shannon, W.B., Hamilton, I.T., 1994. Increased Application of Domestically Produced Plant Fibres in Textiles, Pulp and Paper Production and Composite Materials. Directorate-General XII, Science, Research and Development, European Commission, Brussels. 